\title{
Great Depressions of the Twentieth Century*
}

\author{
Timothy J. Kehoe \\ Department of Economics, University of Minnesota, Minneapolis, Minnesota 55455 \\ and Research Department, Federal Reserve Bank of Minneapolis, Minneapolis, \\ Minnesota 55480 \\ tkehoe@econ.umn.edu \\ and \\ Edward C. Prescott \\ Department of Economics, W. P. Carey School of Business, Arizona State University, \\ Tempe, Arizona 85287 \\ and Research Department, Federal Reserve Bank of Minneapolis, Minneapolis, \\ Minnesota 55480 \\ edward.prescott@asu.edu
}

March 2007

\begin{abstract}
The papers in this volume study twelve great depressions-those in Canada, France, Germany, the United Kingdom, and the United States in the interwar period; those in Argentina, Brazil, Mexico, and Chile during the "lost decade" of the 1980s; those in New Zealand and Switzerland that began in the early 1970s; and another great depression in Argentina that began in 1998. It also studies three not-quite-great depressions - that in Italy in the interwar period and those in Finland and Japan in the 1990s. All of the papers rely on growth accounting to decompose changes in output into the portions due to changes in factor inputs and the portion due to the changes in efficiency with which these factors are used. All of the papers employ simple applied dynamic general equilibrium models. Collectively, these papers indicate that government policies that affect productivity and hours per working-age person are the crucial determinants of the great depressions of the twentieth century.

Journal of Economic Literature Classification Codes: E32, N10, O40.

Key Words: depression, growth accounting, total factor productivity, dynamic general equilibrium

\footnotetext{
*This heavily revised version of our September 2001 paper is the introduction to the volume Great Depressions of the Twentieth Century, published by the Federal Reserve Bank of Minneapolis. The authors of the papers in the volume provided invaluable feedback on this introductory paper. We gratefully acknowledge the support of the National Science Foundation. The data used in the papers in this volume are available at the website http://www.greatdepressionsbook.com. The views expressed herein are those of the authors and not necessarily those of the Federal Reserve Bank of Minneapolis or the Federal Reserve System.
} 
The general equilibrium growth model is the workhorse of modern economics. It is the accepted paradigm for studying most macroeconomic phenomena, including business cycles, tax policy, monetary policy, and growth. Until recently, however, it has been taboo to use the growth model to study great depressions. This volume breaks that taboo. It consists of a collection of papers that use growth accounting and variants of the general equilibrium growth model to examine a number of depressions, both from the interwar period in Europe and America and from more recent times in Finland, Japan, New Zealand, Switzerland, and Latin America.

One view of great depressions is that they are unique events that occurred in the interwar period and are of historical interest only. We disagree with this view. As Figures 1 and 2 illustrate, Argentina, Brazil, Chile, and Mexico had depressions in the 1980s that were comparable in magnitude to those in Canada, France, Germany, and the United States in the interwar period. (Details on the data presented in the figures are given in the appendix.) As Figure 3 illustrates, in recent times New Zealand and Switzerland-rich, democratic countries with market economies - have experienced great depressions. Great depressions are not a relic of the past, and, unless we understand their causes, we cannot rule out their happening again.

The papers in this volume study twelve great depressions - those in Canada, France, Germany, the United Kingdom, and the United States in the interwar period; those in Argentina, Brazil, Mexico, and Chile during the "lost decade" of the 1980s; those in New Zealand and Switzerland that began in the early 1970s; and another great depression in Argentina that began in 1998. It also studies three not-quite-great depressions- that in Italy in the interwar period and those in Finland and Japan in the 1990s.

Much has been written about the Great Depression in the United States and Western Europe in the interwar period. There is no shortage of conjecture about their causes, and there are some interesting recent analyses that use dynamic general equilibrium models to quantitatively explore conjectures. Examples of such analyses include the work of Cooper and Ejarque (1995), Bordo, Erceg, and Evans (2000), Cooper and Corbae (2000), and Harrison and Weder (2001). What makes this volume different is the collective effort that it represents. All of the papers rely on growth accounting to decompose changes in output into three portions: one due to changes in inputs of labor, another due to changes in inputs of capital, and the third due to the changes in efficiency with which these factors are used, measured as total factor productivity (TFP). All of the papers employ simple applied dynamic general equilibrium models with 
aggregate production functions that treat TFP as external to the micro decision makers, but not as invariant to policy.

By studying a number of depressions using a common theoretical framework, the papers collectively establish a set of depression facts and point to directions where future research is needed. To the extent that the depression facts established in this volume foster a better understanding of the factors that give rise to great depressions, they can lead to great depressions becoming a thing of the past.

The growth accounting and applied general equilibrium analysis in this volume yield some surprising results. In sharply defining a number of puzzles, these results direct future research. The results indicating that changes in TFP are crucial in accounting for depressions, for example, direct research to understanding how government policy affects TFP. The methodology developed in this volume can be thought of as a diagnostic tool: it uses macro data and a macro model to determine what factors need to be studied in more detail. The macroeconomic analysis employed here can then be followed up with analyses that use micro data and micro models directed specifically at these factors.

\section{The Growth Model and Growth Accounting}

Our growth accounting is based on the general equilibrium growth model used in all of the papers in this volume. ${ }^{1}$ This growth accounting is closely related to, but differs from, that of Solow (1957), who developed his accounting procedures prior to the development of the general equilibrium growth model in which the consumption-investment decision and the labor-leisure decision are endogenous. The model has two central elements. The first is the technology, which consists of an aggregate production function and an equation that relates the next period's capital stock to the current period's capital stock and investment. The second is a utility function for the stand-in household that depends on the path of consumption and leisure.

The aggregate production function defines the maximum output that can be produced given the quantities of the inputs. With competition, this maximum output is, in fact, the equilibrium output. Further, payments to the factors of production exhaust product. Thus, the

\footnotetext{
${ }^{1}$ Hayashi-Prescott develop this growth accounting in their paper in this volume, although they make a distinction between employment rate and hours per employee.
} 
aggregate production function, along with competitive equilibrium, provides a theory of the income side of the national income and product accounts given the quantities of the factor inputs.

The near constancy of factor income shares across countries and time leads us to the Cobb-Douglas production function

$$
C_{t}+X_{t}=Y_{t}=A_{t} \gamma^{(1-\theta) t} K_{t}^{\theta} H_{t}^{1-\theta}
$$

Here $K_{t}$ is the capital stock in period $t, H_{t}$ hours worked, $C_{t}$ aggregate consumption, and $X_{t}$ aggregate investment. The parameter $A_{t} \gamma^{(1-\theta) t}$ is TFP. It is the efficiency with which inputs are used in producing output and can be thought of as the price of the composite input in terms of the composite output good. The capital stock depreciates geometrically,

(2) $K_{t+1}=K_{t}-\delta K_{t}+X_{t}$.

The stand-in household's utility function is

(3) $\quad \sum_{t=0}^{\infty} \beta^{t} N_{t}^{\phi}\left[\left(c_{t}^{\lambda} v\left(h_{t}\right)^{1-\lambda}\right)^{\rho}-1\right] / \rho$

Here $N_{t}$ is the working-age population, $c_{t}=C_{t} / N_{t}$, and $h_{t}=H_{t} / N_{t}$. We assume that the function $v\left(h_{t}\right)$ satisfies conditions such that utility is concave in $c_{t}$ and $h_{t}$, increasing in $c_{t}$, and decreasing in $h_{t}$. In the limiting case where $\rho=0$, the utility function is

(4) $\quad \sum_{t=0}^{\infty} \beta^{t} N_{t}^{\phi}\left(\lambda \log c_{t}+(1-\lambda) \log v\left(h_{t}\right)\right)$

Suppose that both TFP and the working-age population grow at constant rates, $A_{t} \gamma^{(1-\theta) t}=A_{0} \gamma^{(1-\theta) t}$ and $N_{t}=N_{0} \eta^{t}$. Then this economy has a unique balanced-growth path in which all the quantities per working-age person grow by the factor $\gamma$, with the exception of market hours per working-age person $h$, which is constant. It is this fact that motivates the growth accounting that we adopt.

Our growth accounting rearranges terms in the production function and takes logarithms to decompose the determinants of output into trend and three factors. The advantage of this decomposition is that each of the three factors leads us to examine a different set of shocks and changes in policies when studying changes in output. Using lowercase letters to denote the 
values of variables per working-age person and taking logarithms, we write the production function as

(5) $\quad \log y_{t}=(\gamma-1) t+\frac{1}{1-\theta} \log A_{t}+\frac{\theta}{1-\theta} \log k_{t} / y_{t}+\log h_{t}$.

Along a balanced-growth path, output per working-age person grows at the trend rate and each of the three factors remains constant. External shocks and shifts in policy cause changes in the balanced-growth values of these factors and therefore change the intercept of the balancedgrowth path as well. Constraints imposed upon the way businesses operate, such as a requirement for extra staffing or a restriction on the adoption of a more efficient production technology, will reduce the productivity factor. A change in the tax system that makes consumption more expensive in terms of leisure will reduce the balanced-growth value of the labor factor. A change in the tax system that taxes capital income at a higher level will reduce the balanced-growth value of the capital factor.

An essential feature of the balanced-growth path is that, in the absence of shocks, the equilibrium converges to it. To see this in the simplest possible setting, consider the no-growth case, $\gamma=1$ and $\eta=1$. Dynamic programming yields a policy function $k_{t+1}=g\left(k_{t}\right)$ that increases monotonically, passes through the origin, and intersects the ray with slope 1 once more, at the steady-state value of capital per working-age person, $\hat{k}$. As depicted in Figure 4, the equilibrium path converges monotonically to the steady state $\hat{k}$, where all variables are constant.

With growth, the picture is the same: what converges to a constant is now $k_{t} / \gamma^{t}$, and it converges to the balanced-growth path. To establish this, redefine the variables $c_{t}, k_{t}$, and $x_{t}$ by dividing by $\gamma^{t}$-for example, $k_{t}=K_{t} /\left(\gamma^{t} N_{t}\right)$. The production function in the transformed variables is still

$$
c_{t}+x_{t}=A_{t} k_{t}^{\theta} h_{t}^{1-\theta}
$$

the equation relating current capital and investment to next period's capital is now

$$
\gamma \eta k_{t+1}=(1-\delta) k_{t}+x_{t}
$$

and the utility function is 


$$
\sum_{t=0}^{\infty}\left(\beta \eta^{\phi}\right)^{t}\left[\left(c_{t}^{\gamma} v\left(h_{t}\right)^{1-\gamma}\right)^{\rho}-1\right] / \rho
$$

The transformed economy is stationary, and the transformed $k_{t}$ evolve as pictured in Figure 4 .

In the presence of shocks to $A_{t}$ (and of changes in population growth and so on), we have to add arguments to the policy function, $k_{t+1}=g\left(k_{t}, A_{t}\right)$. Most of the papers in this volume employ simple deterministic models in which consumers perfectly foresee changes in productivity. Amaral-MacGee and Kydland-Zarazaga (henceforth, this is how we will refer to papers in this volume) specify a Markov process over $A_{t}$ to derive the decision rule $k_{t+1}=g\left(k_{t}, A_{t}\right)$. In their numerical experiments, they subject the economy to the observed productivity shocks.

Depressions are not characterized by balanced growth; so we must look at changes in the productivity factor, the capital factor, and the labor factor. On the balanced-growth path, the capital-output ratio is constant, as is the fraction of the time endowment allocated to the market, so its changes contribute nothing. Changes in the capital factor are important for behavior off the balanced-growth path, which is determined by dynamics like those in Figure 4. Similarly, variations in hours worked are important in accounting for growth and depend on the capitaloutput ratio in the determination of the wage and on the tax system through its effect on the relative price of consumption and investment. When converging up to a balanced-growth path, changes in the capital and labor factors are important contributors to economic growth, becoming less important the closer the capital-output ratio is to its balanced-growth value.

Some data illustrate the value of our growth accounting in analyzing large deviations from a balanced-growth path. Figure 5 presents data for the United States over the period 19602000. Notice how close these data are to balanced growth. Growth in output per working-age person $y_{t}$ is driven mostly by growth in the productivity factor $\gamma^{t} A_{t}^{1 /(1-\theta)}$. The capital factor $\left(k_{t} / y_{t}\right)^{\theta /(1-\theta)}$ and the labor factor $h_{t}$ are roughly constant. To be sure, there are deviations, but they are small. Notice how growth in the productivity factor slowed between 1973 and 1982, and how the labor factor grew between 1982 and 2000. Contrast these relatively small deviations from balanced-growth behavior with the large deviations in the data for the United States over the period 1925-39 in Figure 6, which depicts the U.S. Great Depression studied by Cole- 
Ohanian. Here the fall in output per working-age person from 1929 to 1933 is driven by falls in both the productivity factor and the labor factor. After 1933, the productivity factor recovers, but the labor factor does not. Figure 7 presents data for Argentina over the period 1960-2004. Notice that, during the Argentine depression of 1974-90 studied by Kydland-Zarazaga, the fall in output per working-age person is driven by the fall in the productivity factor and the labor factor stays roughly constant. In contrast, during the 1998-2002 Argentine depression studied by Kehoe, the fall in output per working-age person is driven by falls in both the productivity factor and the labor factor.

\section{Definition of a Great Depression}

We follow the work of Schumpeter (1935) and Lucas (1977) and represent output per working-age person as trend and deviation from trend. If output is significantly above trend, the economy is in a boom. If it is significantly below trend, the economy is in a depression. There also are seasonal components, and there are short-term negative deviations resulting from financial crises, such as the three that occurred in the United States in the 1890-1909 period.

This leaves open the question of what is a good definition of trend. We use growth theory to define trend. Output per working-age person depends both on the accumulation and employment of factors of production and on the efficiency with which these factors are used. Absent changes in the capital-output ratio or hours worked per working-age person, growth in the potential output per working-age person is due to increases in the stock of knowledge useful in production. Our view is that this stock increases smoothly over time and is not countryspecific. Consequently, holding economic institutions constant, this growth in knowledge is what gives rise to the trend growth rate. ${ }^{2}$ Using the production function (5), we write

(9) $\quad \hat{y}_{t}^{i}=\gamma^{t} \hat{y}_{0}^{i}$

as trend growth of output per working-age person in country $i$ in the absence of changes to the productivity factor or the input factors.

\footnotetext{
${ }^{2}$ The trend growth rate of the productivity factor also reflects the fact that, as societies become richer, they choose to impose constraints on production practices that reduce output per unit of input. Societies rationally impose these constraints to mitigate negative externalities, to promote positive externalities, and to promote equity.
} 
Trend is defined relative to the average growth rate of the industrial leader. In this volume, we use a trend growth rate of 2 percent per year because this rate is the secular growth rate of the U.S. economy in the twentieth century, $\gamma=1$.02. Figure 8 shows the economic performance of the United States in terms of real GDP per working-age person over the twentieth century. Notice how close the data are to a trend line of 2 percent growth per year, except during the U.S. Great Depression of 1929-39 and the World War II buildup of 1939-46. The United States is large, diverse, and politically stable, and it was the industrial leader throughout the twentieth century. Perhaps in the twenty-first century, the European Union or China will become the industrial leader, and it will be appropriate to define the trend growth rate relative to that economy rather than to the U.S. economy.

Other countries have a level of the productivity factor that is a function of each country's institutions at any particular time. On the balanced-growth path, this level is the factor $\hat{y}_{0}^{i}$ in (9). The institutions that determine $\hat{y}_{0}^{i}$ include tax systems, but taxes are probably more important as determinants of the input factors. Perhaps more important, these institutions include openness to foreign competition, industrial regulations, banking systems, and bankruptcy procedures. We would expect, absent changes in institutions, that the trend growth of a country's productivity factor would be the same as that of the United States.

Changes in institutions, however, can raise or lower the level of the productivity factor. For example, Cole-Ohanian find that the trend path for the institutions that prevailed in the United Kingdom in 1920 is about 20 percent below the trend path associated with institutions that prevailed prior to World War I. Given the economic institutions that prevail in a country at a point in time, the trend of that country is the associated balanced-growth path of the growth model. All trends, which differ across countries, have the same slope. ${ }^{3}$

To be a great depression, a negative deviation from trend must satisfy three conditions.

First, it must be a sufficiently large deviation. Our working definition is that a great depression is a deviation of at least 20 percent below trend. Second, the deviation must occur rapidly. Our working definition is that detrended output per working-age person must fall at least 15 percent

\footnotetext{
${ }^{3}$ That the trend was 2 percent throughout the twentieth century does not imply that it will remain at this level in the future.
} 
within the first decade of the depression. Third, the deviation must be sustained. Our working definition is that output per working-age person should not grow at the trend growth rate during any decade during the depression.

We can make this definition explicit using our notation. A time period $D=\left[t_{0}, t_{1}\right]$ is a great depression if

1. There is some year $t$ in $D$ in such that $\left[y_{t}^{i} /\left(\gamma^{t-t_{0}} \hat{y}_{t_{0}}^{i}\right)\right]-1 \leq-0.20$.

2. There is some $t \leq t_{0}+10$ such that $\left[y_{t}^{i} /\left(\gamma^{t-t_{0}} y_{t_{0}}^{i}\right)\right]-1 \leq-0.15$.

3. There are no $t_{1}, t_{2}$ in $D, t_{2} \geq t_{1}+10$, such that $\left[y_{t_{2}}^{i} /\left(\gamma^{t_{2}-t_{1}} y_{t_{1}}^{i}\right)\right]-1 \geq 0$.

Notice that we do not require that an economy return to the original trend path at the end of a depression. Because of changes in institutions, the country might have a new, lower level of its productivity factor. We would, however, expect the productivity factor, and eventually the economy itself, to grow at the trend rate.

To see if a country has experienced a depression, we typically look only at detrended output per working-age person to see if it has fallen sufficiently far and sufficiently rapidly starting at any point in time. In other words, we identify the trend level $\hat{y}_{t_{0}}^{i}$ with the observed level $\hat{y}_{t_{0}}^{i}$ in the first part of our definition. In some cases, however, it is reasonable to believe the economy is above or below trend when the depression started. That investment was so high relative to output in France in 1930, for example, suggests that the economy was below the trend associated with its 1930 policies. If so, absent policy changes, French output per working-age person should have grown at a rate in excess of 2 percent in the 1930s, following the sort of nonbalanced-growth dynamics depicted in Figure 4.

By our definition of great depression, New Zealand experienced a great depression during the period 1974-92. As the data in Figure 3 show, detrended output per working-age person fell more than 32 percent between 1974 and 1992, with a decline of more than 18 percent between 1974 and 1983. Switzerland is currently experiencing a great depression that began in 1973. Detrended output per working-age person in Switzerland fell more than 30 percent between 1973 and 2000, with a decline of more than 18 percent between 1973 and 1983. Figure 
3 is useful for making the point that depressions are not a thing of the past, even in rich industrial countries.

The interwar Italian depression and the recent Finnish and Japanese depressions are the only ones studied in this volume that are not great. Although detrended output per capita fell more than 15 percent in Italy between 1929 and 1934, at no point in the interwar period did it fall 20 percent. The decline in detrended output per working-age person in Finland in 1989-93 was only 19 percent. The decline in detrended output per working-age person in 1992-2002 in Japan was only 14 percent.

The second part of the definition of a great depression is that there is a rapid decline in detrended output. According to Maddison (1995), output per capita in the United Kingdom fell dramatically during the period 1871-1910 relative to that in the United States. It was during this period of long, slow secular decline, in fact, when the United Kingdom surrendered its position as industrial leader to the United States. Yet, even if we use the trend growth rate of 2 percent that is appropriate for the twentieth century - but is probably too high for the nineteenth century - detrended output per capita did not fall by 15 percent in the first decade of the decline. Consequently, we do not say that the United Kingdom experienced a great depression during this period.

\section{The Productivity Factor}

The productivity factor turns out to be an important contributor to a majority of the depressions studied in this volume. Cole-Ohanian show that the productivity factor accounts for much of the decline in the U.S. Great Depression. Given that it returned to trend in the second half of the 1930s, however, the productivity factor was not the reason that the U.S. economy was still depressed in 1939, being 20 percent below trend.

As reported by Bergoeing-Kehoe-Kehoe-Soto in their paper in this volume, both Mexico and Chile had great depressions in the early 1980s, with output falling 30 percent below trend within a few years. The crises that set off these depressions were similar in nature. Both countries were big international debtors and were hit by shocks. The first shock was the increase in the world real interest rate. The second was that the price of an important export fell-and fell dramatically. In the case of Mexico, the export was oil; in the case of Chile, copper. 
Bergoeing-Kehoe-Kehoe-Soto find that, if we are to interpret these factors as the causes of the depressions in Mexico and Chile, then they must have operated through mechanisms that affect the productivity factor, rather than the input factors. Inputs during the depression behaved as theory predicts. Subsequent to the sharp decline in output, the behavior of the two countries was very different. In Chile, TFP recovered and the economy returned to trend. Actually, it returned to a level about 20 percent above trend, but this added 20 percent seems to have been due to a large cut in tax rates in the mid-1980s that changed the balanced-growth capital factor. Mexico failed to recover and in 1995 was still 30 percent below trend. The reason for the difference in recoveries of these two countries was the difference in the behavior of TFP. In fact, changes in fiscal policy in Mexico seem to have had similar beneficial effects to those in Chile.

The question then is, Why did TFP behave so differently in Mexico and Chile subsequent to 1983 ? Bergoeing-Kehoe-Kehoe-Soto marshal evidence that points to differences in the banking systems and bankruptcy laws in the two countries. Chile reformed its banking and bankruptcy procedures, while Mexico did not. Chile let unproductive firms go bankrupt and allowed new investments to be determined by market interest rates. In Mexico, in contrast, the banking system was controlled by the government, which channeled low-interest-rate loans to some firms, and not others, regardless of their productivity. Bergoeing-Kehoe-Kehoe-Soto sketch out a model, based on work by Atkeson and Kehoe (1995) and Chu (2001), in which such distortionary policies can have large negative effects on TFP.

Amaral-MacGee find an interesting difference in the behavior of the U.S. economy and the Canadian economy in the 1929-39 period. The paths of output per working-age person were similar, as was the contribution of the productivity factor to the decline. What is different is that, in Canada, TFP did not return to trend. Canadian output per working-age person was 25 percent below trend in 1939, largely because of low TFP. Their analysis indicates that any explanation of the Great Depression in Canada will have to explain why TFP did not recover in Canada as it did in the United States.

Hayashi-Prescott study the Japanese depression that began in 1992. They find that the calibrated values of the basic growth model with its aggregate production function and stand-in household for Japan and the United States are virtually identical. The behavior of TFP was very different in the two countries, however. In Japan, the productivity factor, after growing at a rate in excess of 3 percent from 1984 to 1991, began growing at 0.3 percent in the 1991-2000 period. 
In contrast, the productivity factor in the United States grew at a rate of 1.8 percent in the 1980s and 2.2 percent in the 1990s. It is remarkable how closely the Japanese economy in the 1990s behaved in line with the predictions of theory. The deepening of capital and the associated fall in return on capital were just as the theory predicted. The decline in hours per working-age person was also as theory predicts, although this decline was also affected by a policy that reduced the workweek length from forty-four hours to forty hours in the 1989-92 period. The analysis directs future research to understanding why productivity did not grow in Japan as it did in the United States and the European Union in the 1990s.

Kydland-Zarazaga find that the sharp fall in the productivity factor between 1979 and 1990 accounts for most of the decline in output per capita in Argentina. The case is different in the recovery in Argentina during 1990-97: Kydland-Zarazaga find that the economy recovered only about half as much as their model predicts. Kehoe finds that the more recent (1998-2002) depression in Argentina has also been associated with a fall in the productivity factor. BugarinEllery-Gomes-Teixeira find that the depression in Brazil in the 1980s was driven by a fall in the productivity factor, although output failed to recover in the 1990s as productivity recovered. Kehoe-Ruhl find that declines in the productivity factor account for almost all of the depressions in New Zealand and Switzerland in the late twentieth century.

Fisher-Hornstein find that in Germany, the decline in the productivity factor and its interaction with wage-setting policies were the most important contributors to the decline and recovery. The policy changes or shocks that caused TFP in Germany to drop in 1928-32 have yet to be identified. A very different picture emerges with respect to the interwar depressions in France, Italy, and the United Kingdom. In these countries, the productivity factor played a minor role.

\section{The Labor Factor}

Policies that altered the balanced-growth labor factors are also very important in accounting for depressions. Cole-Ohanian find that the labor input in the United Kingdom was 20 percent below what it was prior to World War I throughout the entire interwar period. The investment share of product remained at its historic norms, however, so the U.K. economy was close to a balanced-growth path beginning in 1920. An interesting and unique feature of the British Depression is that it began in 1920, nearly ten years before it began in other countries, 
including the five other depressions from the 1930s examined in this volume. Cole-Ohanian come to the conclusion that generous unemployment benefits, in conjunction with large sector shocks, were the probable reason for the low labor input. Their analysis defines a puzzle and proposes a possible resolution.

The behavior of the French economy is different from that of the other major industrial countries. Beaudry-Portier find that the French economy declined smoothly relative to trend in the 1929-38 period, which is unlike what happened in either Germany or the United States. They argue that it is possible to understand the French Depression as a transition between a higher and a lower balanced-growth path. They find that TFP was not an important factor in the French Depression once the capital utilization rate is taken into account and vintage capital is introduced. This study points to the need for a better understanding of the institutional factors that resulted in a lower balanced-growth path. Perhaps tax increases or changes in the nature of labor bargaining are important in understanding this change.

The third depression for which the labor factor played the key role is Germany in the period 1928-37. Fisher-Hornstein find that the nearly 40 percent decline in output relative to trend in 1928-32 was due in large part to the policies that resulted in the real wage being set above the market-clearing level. There was an interesting interaction of the policy that maintained real wages fixed with the fall in the productivity factor: it was the drop in TFP that caused the market-clearing wage to fall sharply, making the real-wage policy more distortionary. Once these policies were eliminated and wages were again market-determined, the German economy recovered as theory predicts. One component of output did not recover, namely private consumption. The decrease in private consumption was offset on an almost one-for-one basis by public consumption. The German experience in the 1928-37 period is in remarkable conformity with theory, and there are no puzzles.

Tax policy can have large effects on the labor factor. Prescott argues that high taxes on labor in France has led to hours worked being 30 percent lower there than in the United States in 2000. Bugarin-Ellery-Gomes-Teixeira argue that increases in labor taxes in Brazil caused hours worked there to decline in the 1990s, even though productivity was increasing following its sharp drop in the 1980s. Conesa-Kehoe-Ruhl further argue that increases in taxes in Finland were associated with much of the fall in labor there in the 1990s. 


\section{The Capital Factor}

The capital factor seems to have played a relatively minor role in the depressions studied in this volume. Its biggest influence seems to have been in the three Latin American countriesArgentina, Mexico, and Chile—in the late 1980s and 1990s. Kydland-Zarazaga find that the capital-output ratio in Argentina did not increase as fast as the model predicts, dampening the recovery. In contrast, Bergoeing-Kehoe-Kehoe-Soto find that the capital-output ratio in both Mexico and Chile increased faster than the model predicts, mitigating the depression in Mexico and turning the recovery in Chile into a growth miracle.

In the cases of Mexico and Chile, the increases in the capital factor can be accounted for by a tax reform that lowered the distortion in the consumption-investment decision. Such tax reforms did indeed occur in the 1980s in Mexico and Chile, and in the case of Chile at least, the change in the tax rate was remarkably close to the one that Bergoeing-Kehoe-Kehoe-Soto calibrate to the change in investment behavior. Kydland-Zarazaga speculate that the discrepancy between the model's predictions for Argentina and the data is the result of not modeling Argentina as an open economy. The results for Mexico and Chile cast some doubt on this conjecture, however: these two countries were far more open than Argentina, and the capital factor was increasing faster than expected there at exactly the same time that it was increasing more slowly than expected in Argentina.

It is worth stressing that the severity of Mexico's depression was not caused by a lack of funds for investment at the macro level. Investment in Mexico was higher than the model predicts. The problem in Mexico, as Bergoeing-Kehoe-Kehoe-Soto stress, was the allocation of investment at the micro level. Hayashi-Prescott find a similar situation in Japan: the micro evidence indicates that Japanese firms, both large and small, did not lack funds for investment. Other funding sources were found that offset the large decrease in bank lending. The problem in Japan is that firms seem to have lacked good investment opportunities.

\section{Other Factors}

Factors besides those emphasized by our growth accounting do not play major roles in any of the depressions, except in the cases of Germany and Italy. Hornstein-Fisher find that increased government spending usurped private consumption during the recovery period in 
Germany. The distortionary nature of the taxes used to finance this increased government spending had a negative, but small, effect on output.

Perri-Quadrini find that the collapse of world trade during the late 1920s and 1930s was the major determinant of the not-quite-great depression in Italy. To understand how a decline in trade can reduce output, consider an aggregate production function that is similar to that employed by Perri-Quadrini, $A F(K, H, M)$, where $M$ is imports that are used as intermediate goods and $F$ is constant returns to scale. With this production technology, gross domestic product is

$$
Y=A F(K, H, M)-(1+\tau) p_{M} M .
$$

Increases in trade barriers $\tau$ or in the relative price of imports $p_{M}$ cause a fall in imports, but this has no first-order effect on GDP, since $(1+\tau) p_{M}=A F_{M}(K, H, M)$ implies that

$$
Y=A F_{K}(K, H, M) K+A F_{H}(K, H, M) H .
$$

What is crucial is the effect that a decline in imports has on the marginal products of domestic inputs, which depend on the cross partial derivatives $F_{K M}(K, H, M)$ and $F_{H M}(K, H, M)$. These cross effects are governed by the elasticities of substitution between imports and the other inputs in the production function. It is worth noting that these cross effects would show up in a similar way to changes in TFP in the production function

$$
A F\left(K, H, M\left(K, H ; \tau, p_{M}\right)\right)=\max _{M} A F(K, H, M)-(1+\tau) p_{M} M .
$$

Perri-Quadrini argue that, for reasonable values of substitution elasticities, the decline in imports from 19 percent of GDP in Italy in 1929 to 7 percent in 1936 can account for most of the decline in GDP there. They further argue that observed increases in trade barriers can roughly account for the observed decline in trade. Crucini-Kahn argue that increases in trade barriers can account for a modest fraction of the decline in the United States during the Great Depression.

Amaral-MacGee find that negative terms-of-trade shocks—which include anything that increases the relative price of imports to exports—-played a more minor role in the Canadian Great Depression. Bergoeing-Kehoe-Kehoe-Soto point out that changes in trade may have played important roles in both Mexico and Chile, just not in determining the differences in their recovery paths. It is easy to see in the production function (12) how the terms-of-trade shocks 
show up as a negative shock to TFP in Mexico and Chile at the beginning of their depressions. Trade also undoubtedly was a crucial factor in the not-quite-great depression in Finland in 198993 studied by Conesa-Kehoe-Ruhl, where output per working-age person fell 19 percent below trend during the breakup of the Soviet Union. The beginnings of the depressions in New Zealand and Switzerland studied by Kehoe-Ruhl were both associated with the oil price shock of the early 1970s. Obviously, trade policy, and external shocks in general, merit further study within our framework.

\section{The Picture That Emerges}

Collectively, the papers in this volume indicate that government policies that affect TFP and hours per working-age person are the crucial determinants of the great depressions of the twentieth century. Taxes and other policies that reduce the incentive to accumulate capital can also depress an economy. In the depressions studied in this volume, however, there was no case of this happening. In fact, policy changes that increased this incentive in Mexico and Chile were put in place in the mid-1980s. In the case of Mexico, this policy change mitigated its depression, while in Chile it led to the growth miracle that accompanied the recovery from its slump. Factors like trade liberalization and privatization probably also had effects on TFP and on capital accumulation in both Mexico and Chile, but do not seem to have been crucial in driving the differences in their recovery patterns.

Given the behavior of TFP in Latin America in the 1980s and in Japan in the 1990s, the depressions there are what theory predicts. An implication of this finding is that the quantity of savings is not the problem and that subsidies to investment are not the solution. ${ }^{4}$ The question is, What policies impede growth in the productivity factor? Absent careful micro studies at the firm and industry level, we can only conjecture as to what these policies are. Our conjecture is that competition and letting inefficient firms fail has major consequences for productivity. This conjecture is based on careful studies in manufacturing, construction, and mining industries: Baily and Solow (2001), for example, find that "when an industry is exposed to the world's best practice, it is forced to increase its own productivity.” Holmes and Schmitz (2001) document

\footnotetext{
${ }^{4}$ A decrease in the tax rate on capital income will raise the balanced-growth path and is a good policy from a public finance perspective.
} 
how competition from railroads in the late nineteenth and early twentieth centuries forced longshoremen in the United States to drop inefficient work practices. Cartelization and subsidies are another mechanism to preserve the status quo and to protect those with vested interests. ${ }^{5}$ What incentive is there to adopt more efficient production methods if less efficient competitors are subsidized? Empirically, inefficient organizations become efficient when they have to.

Further evidence that policy matters is that relative industry TFPs differ-and differ a lot-across the rich industrial countries. Baily and Solow (2001) report that the Japanese auto industry's TFP is one and one-half times that of the U.S. auto industry. In the service sector, where competition is limited, Japan is only half as productive as the United States.

Still another policy that can adversely affect productivity is one that channels investment to inefficient producers. Perhaps, in the 1990s, after the stock market and land market bubbles in Japan burst, the government did not want the embarrassment of a collapse of the banking system. To avoid default, loans were made to producers at interest rates below the market rate that would otherwise have defaulted on bank loans.

Labor market policies are also of great importance. In the case of the German Great Depression and its recovery phase, the real-wage policy that followed played the crucial role. In neither France nor the United Kingdom has the policy that gave rise to the Great Depression in the interwar period been documented. Cole-Ohanian have a conjecture for the United Kingdom based on some strong evidence. In the case of France, it will be interesting to see whether taxes that increased the price of consumption relative to leisure were cause. Another promising area of inquiry is the role of cartelization in affecting balanced-growth hours per working-age person. Cole and Ohanian (2001) find that industry cartelization with a specific set of bargaining rules might account for the failure of the U.S. economy to recover from the Great Depression in 193539.

\footnotetext{
${ }^{5}$ Parente and Prescott (2000) consider an economy in which policy has a large consequence for the TFP factor. The analysis is a dynamic general equilibrium model with cartelized industries and imperfect competition. If the state protects industry insiders from competition, TFP will be much lower than it would be absent protection.
} 


\section{Appendix}

\section{Data for Figure 1}

The data for Canada are real gross domestic product (GDP) per civilian older than 14. The data for real GDP are from Statistics Canada, National Income and Expenditure Accounts: Annual Estimates 1926-1986 (1988). The data for population older than 14 are taken from Statistics Canada, Historical Statistics of Canada (2001), http://www.statcan.ca. The data from France are real GDP per capita from Beaudry-Portier. The data for Germany are real GDP per capita from Hornstein-Fisher. The data for the United States are real GDP per person older than 16. The real gross national product (GNP) series is from Kendrick, Productivity Trends in the United States (Princeton University Press, 1961). The series for population older than 16 is from U.S. Bureau of the Census, Current Population Reports (1965).

\section{Data for Figures 2 and 3}

All data are real GDP per working-age person (15 to 64). The real GDP series are indexes of real GDP volume from the International Monetary Fund's International Financial Statistics. The population of working age is from the World Bank's World Development Indicators 2004 CDROM.

\section{Data for Figures 5, 6, and 7}

The data in Figure 5 are from Conesa-Kehoe-Ruhl. The data in Figure 6 are from Cole-Ohanian. The data in Figure 7 are from Kehoe.

\section{Data for Figure 8}

The data in Figure 8 are from Prescott. 


\section{References}

Atkeson, Andrew, and Patrick J. Kehoe. 1995. Industry evolution and transition: Measuring investment in organization capital. Research Department Staff Report 201. Federal Reserve Bank of Minneapolis.

Baily, Martin N., and Robert M. Solow. 2001. International productivity comparisons built from the firm level. Journal of Economic Perspectives 15 (3): 151-72.

Bordo, Michael D.; Christopher J. Erceg; and Charles L. Evans. 2000. Money, sticky wages, and the Great Depression. American Economic Review 90 (5): 1447-63.

Chu, Tianshu. 2001. Exit barriers and economic stagnation. Manuscript. East-West Center.

Cole, Harold L., and Lee E. Ohanian. 2001. New Deal policies and the persistence of the Great Depression: A general equilibrium analysis. Working Paper 597. Federal Reserve Bank of Minneapolis.

Cooper, Russell W., and Dean Corbae. 2000. Financial fragility and active monetary policy: A lesson from the Great Depression. Manuscript. Boston University.

Cooper, Russell W., and Joao Ejarque. 1995. Financial intermediation and the Great Depression: A multiple equilibrium interpretation. Carnegie-Rochester Conference Series on Public Policy 43 (December): 285-323.

Harrison, Sharon G., and Mark Weder. 2001. Did sunspots cause the Great Depression? Manuscript. Bernard College.

Holmes, Thomas J., and James A. Schmitz. 2001. Competition at work: Railroads vs. monopoly in the U.S. shipping industry. Federal Reserve Bank of Minneapolis Quarterly Review 25 (Spring): 3-29.

Lucas, Robert E. 1977. Understanding business cycles. In Stabilization of the domestic and international economy, ed. Karl Brunner and Allan H. Meltzer, Vol. 5. CarnegieRochester Conference Series on Public Policy. Amsterdam: North-Holland, 7-29. 
Maddison, Angus. 1995. Monitoring the world economy: 1820-1992. Development Centre Studies. Paris: Organisation for Economic Co-operation and Development.

Parente, Stephen L., and Edward C. Prescott. 2000. Barriers to riches. Cambridge, MA: MIT Press.

Schumpeter, Joseph A. 1935. The analysis of economic change. Review of Economic Statistics 17 (May): 2-10.

Solow, Robert M. 1957. Technical change and the aggregate production function. Review of Economics and Statistics 39 (August): 312-20. 
Figure 1.

Detrended output per person during the Great Depression

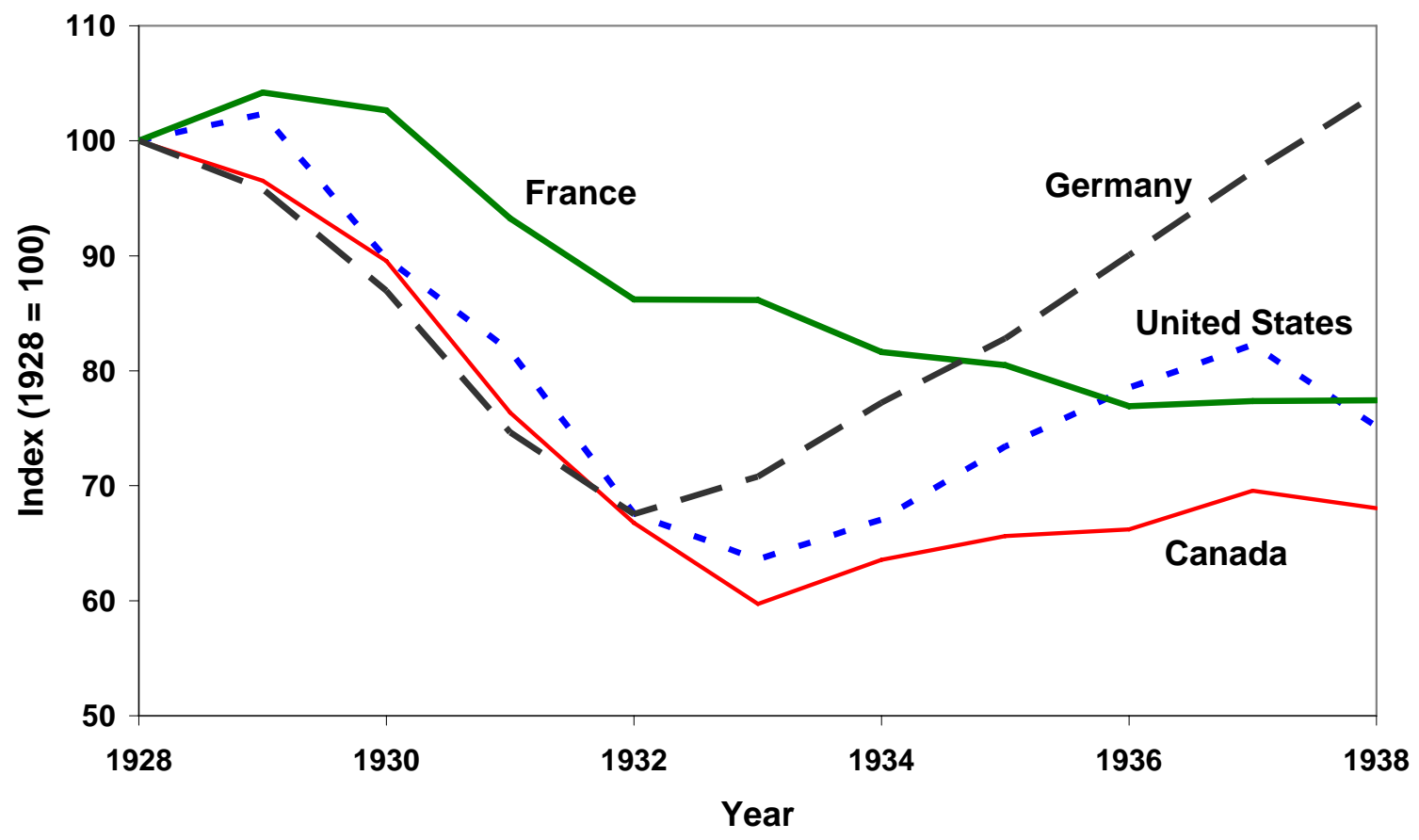

Figure 2.

Detrended output per working-age person during the 1980s in Latin America

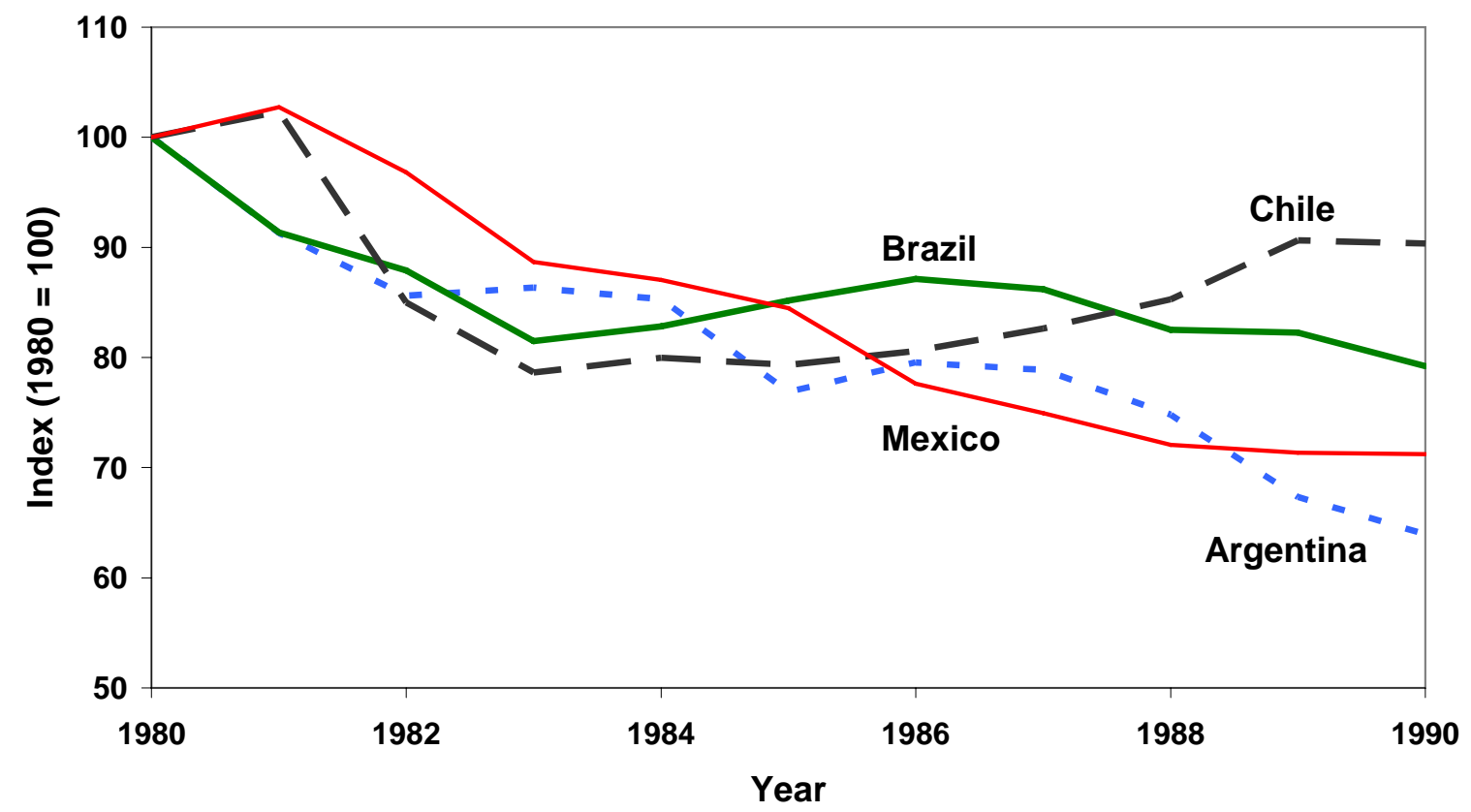


Figure 3.

Detrended output per working-age person in New Zealand and

Switzerland 1970-2000

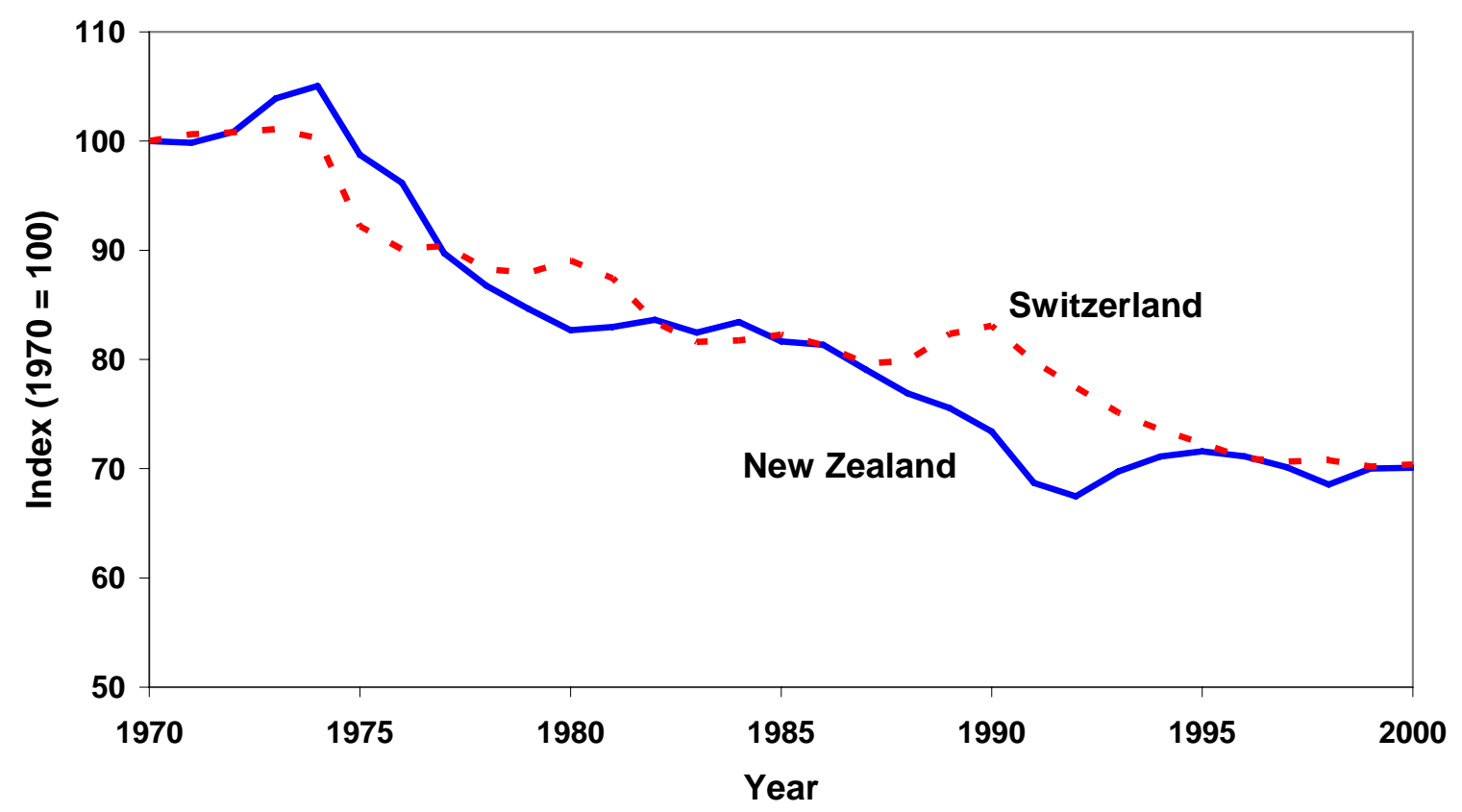

Figure 4.

Dynamics in the growth model

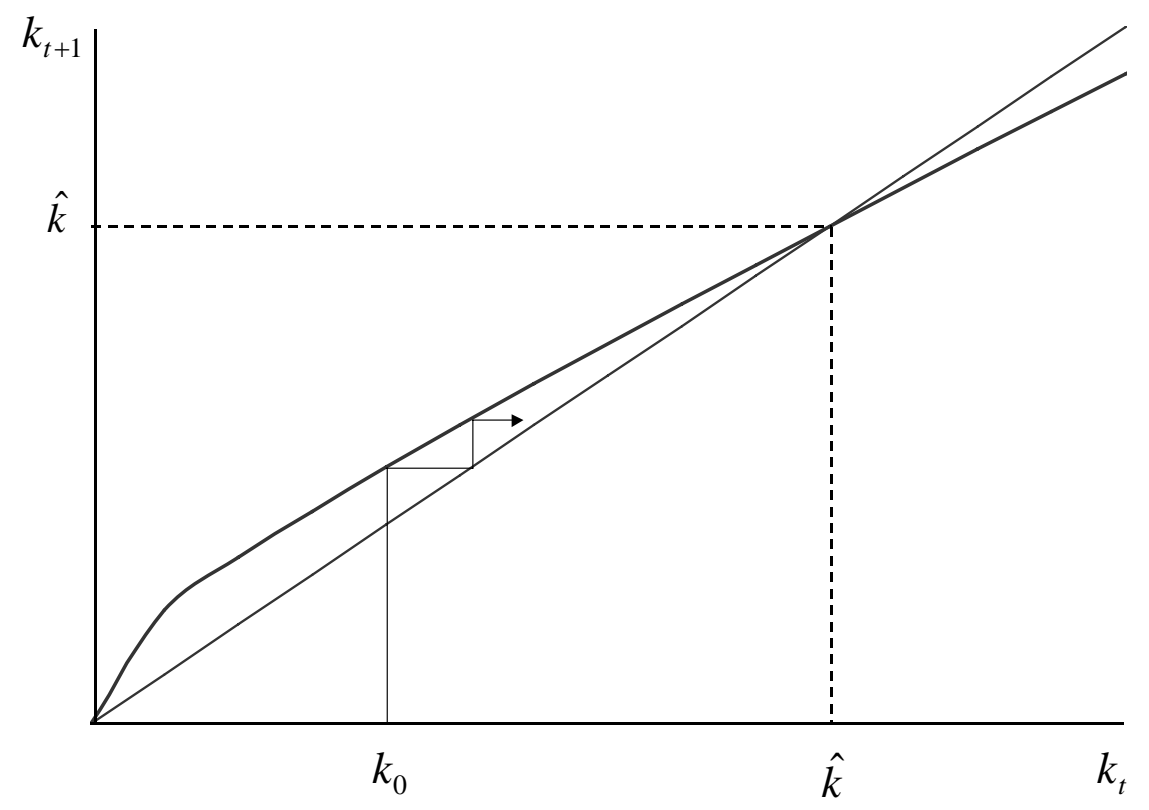


Figure 5.

Growth accounting for the United States, 1960-2000

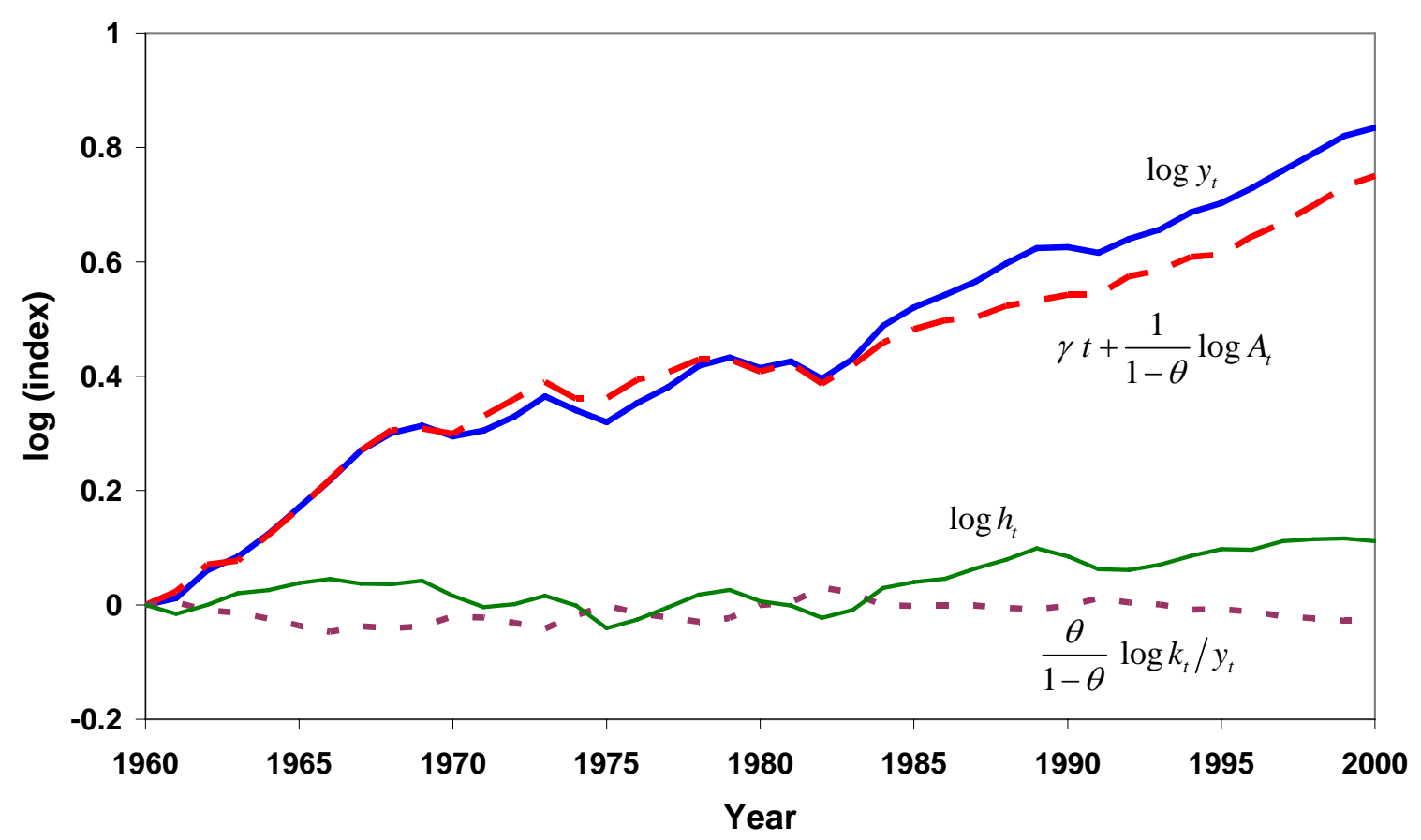

Figure 6.

Growth accounting for the United States, 1925-1939

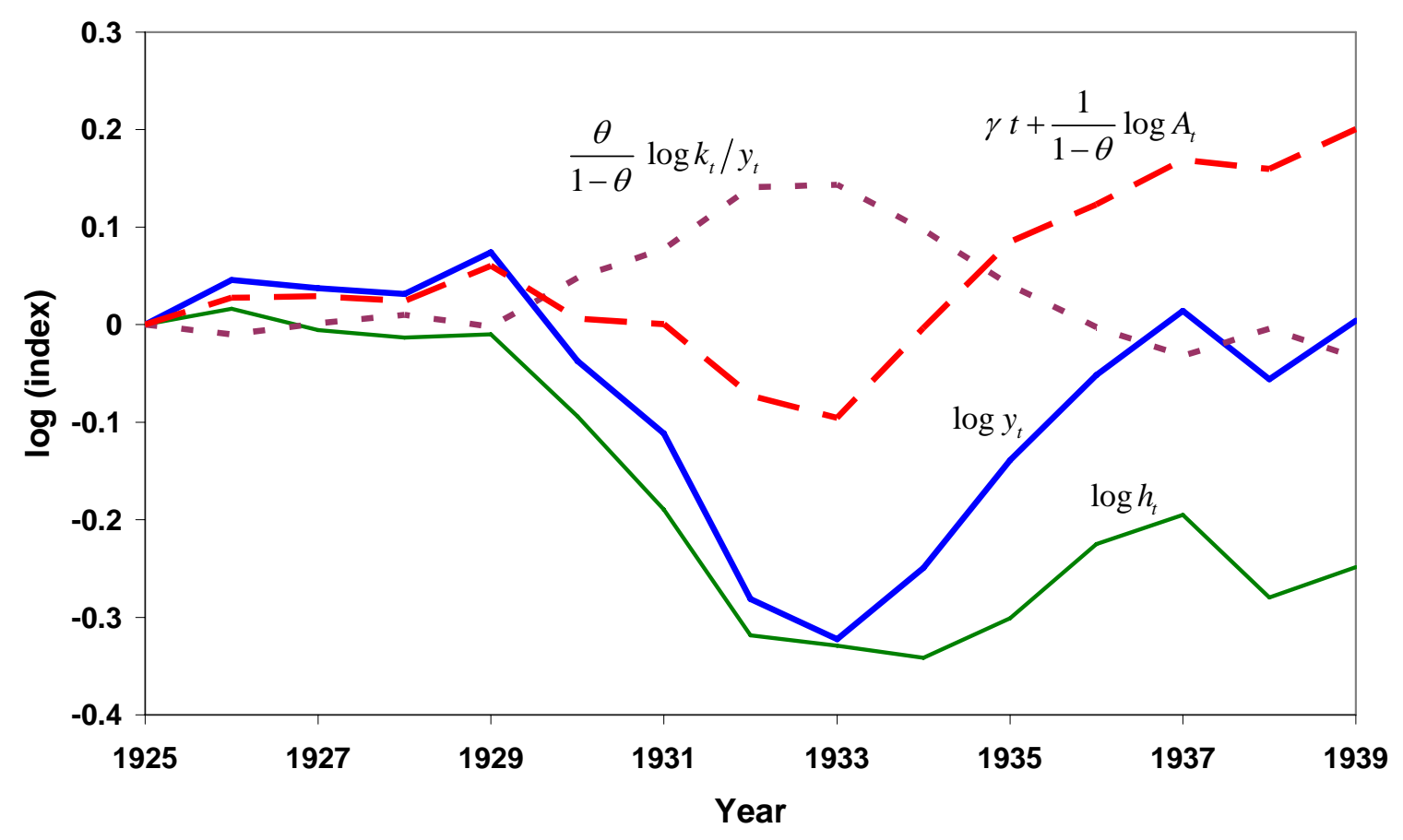


Figure 7.

Growth accounting for Argentina, 1960-2004

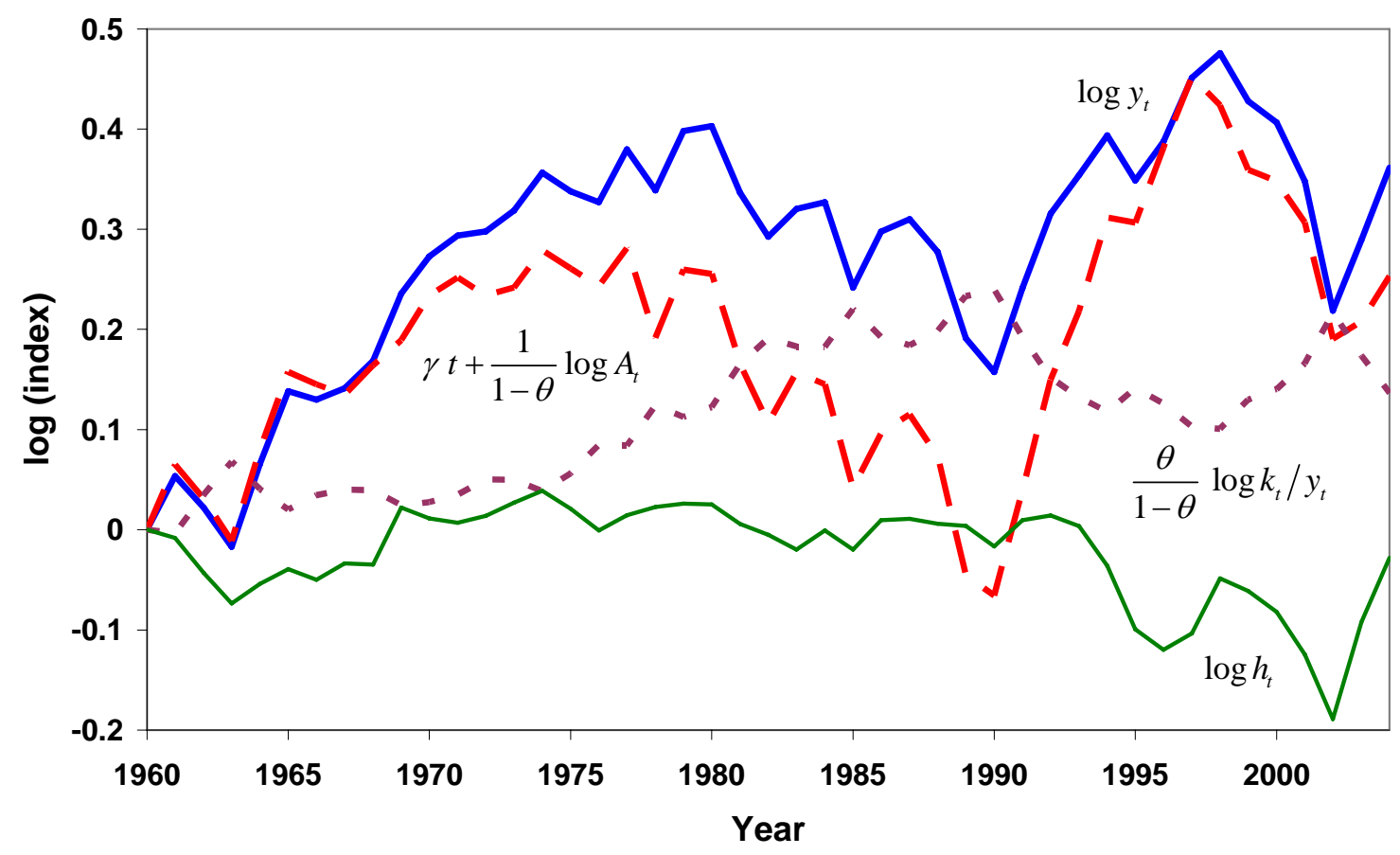

Figure 8.

Real GDP per working-age person in the United States, 1900-2000

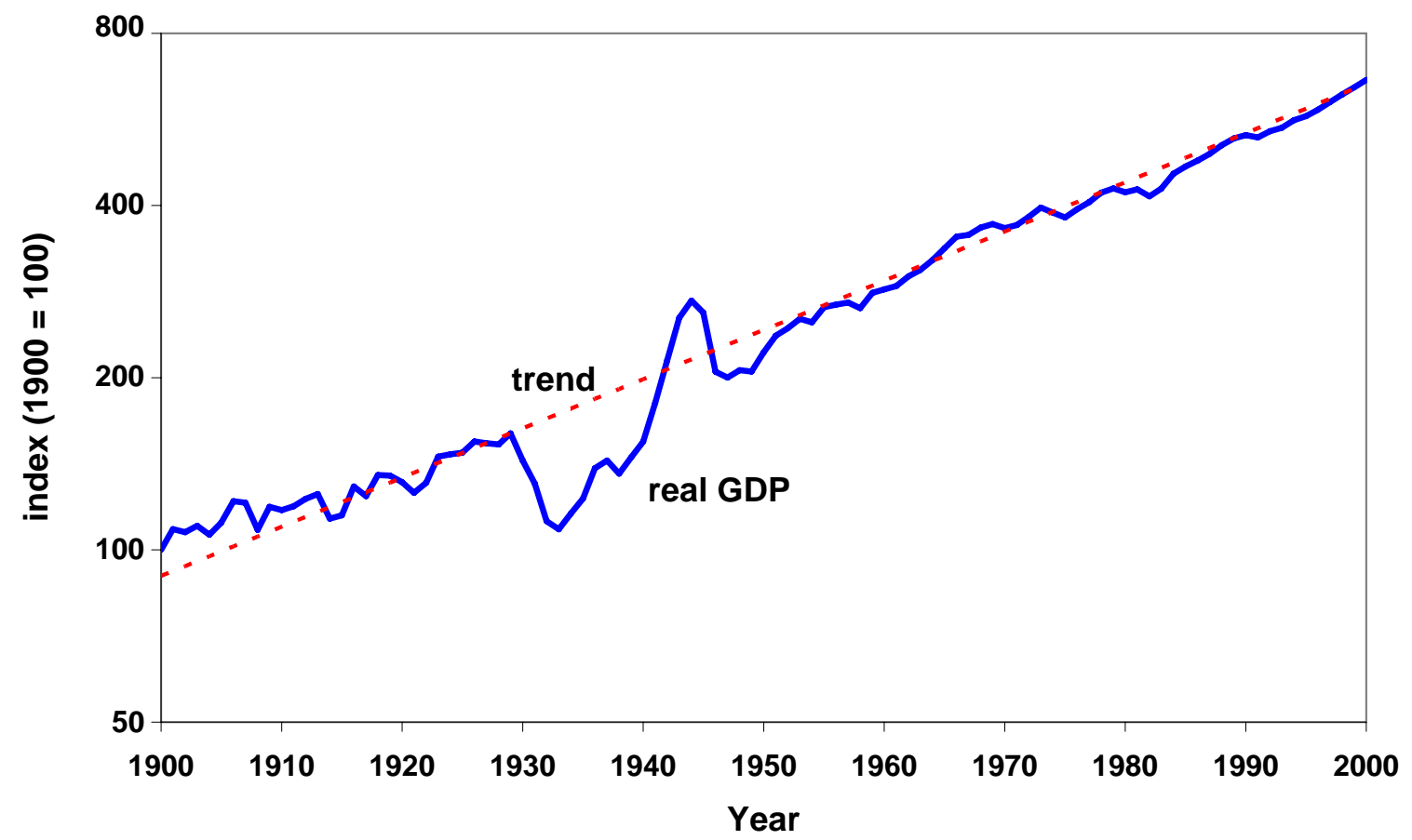

